\title{
Mercosul e a Liberdade de Concorrência
}

\section{Augusto Jaeger Junior ${ }^{1}$}

Sumário: Introdução. 1. Mercosul: fases da integração e as liberdades fundamentais. 2. A União Européia e a liberdade de concorrência. 3. O Mercosul e a liberdade de concortência. 4. Políticas públicas e a liberdade de concorrência. Considerações Finais. Referências bibliográficas.

\section{Introdução}

A presente apresentação se centrará na análise da telação existente entre os auxílios concedidos pelos Estados às empresas próprias, ou outras, e o tratamento dado à liberdade de concorrência em determinados processos de integração.

Pretende, ainda, demonstrar a necessidade da correta utilização das políticas públicas para a garantia da proteção da liberdade de concorrência comercial e os efeitos da utilização incorreta dessas, especialmente quanto ao retardamento do atingimento de tal liberdade e a conseqüente não conformação da fase de mercado comum, um dos objetivos do Tratado de Assunção.

\section{Mercosul: fases da integração e as liberdades fundamentais}

O fenômeno da integração econômica, ocorrido neste final de século, propiciou a crescente globalização dos mercados mundiais e a formação de blocos rcgionais atuando entre si, através de um crescente fluxo comercial, com o objetivo de produzir o desenvolvimento dos países, a partir de estímulos econômicos gerados

\footnotetext{
${ }^{1}$ Mestre em Direito Internacional pela UFSC, Brasill, e autor do livro "Mexcosul e a livre circulação de pessoas", lançado pela Editora LTr, de São Paulo. É professor da Universidade Regional Integrada do Alto Uruguai e das Missōes, campus de Santo Ângelo (RS/Brasil), do Instituto de Ensino Superior de Santo Angelo e da Universidade Luterana do Brasil, campus de Canoas. É docente convidado da disciplina de Negócios no Mercosuł, do Mestrado em Administração Estratégica de Negócios da Faculdade de Administraçāo, Economia e Negócios da Universidade Nacional de Formosa, República Argentina.
} 
pela criação de um mercado consumidor mais vasto, pelo qual devem fluir, com mais facilidades, os bens produzidos e os serviços executados nos Estados-partes integrados.

Nesse sentido, a integração do Cone Sul tomou força na segunda metade da década de oitenta, principalmente com o retorno dos países ao regime democtático de governo e com a assinatura, em 1988, do Tratado de Integração, Cooperação e Desenvolvimento. Essa nova proposta integracionista culminou com a assinatura, em 1991, do Tratado de Assunção, instituidor do Mercado Comum do Sul (Mercosul) entre Brasil, Argentina, Paraguai e Uruguai. Esse documento objetiva a constituição de um mercado comum, estando seus Estados-partes atualmente consolidando a etapa da união aduaneira.

Do exposto no artigo $1^{\circ}$, do Tratado de Assunção, se observa que o objetivo desse processo de integração é constituir um mercado comum, que deveria estar estabelecido até 31 de dezembro de 1994 e que se denominaria Mercado Comum do Sul. A fase de mercado comum enseja a presença das cinco liberdades fundamentais e, ainda, a regulamentação de diversos assuntos necessários pata o seu pleno funcionamento.

Porém, tal progresso não foi atingido no prazo previsto. O Protocolo de Ouro Preto, surgido naquela época, em seu Preâmbulo, deixa evidente esse não-atingimento ao expressar a importância dos avanços alcançados até então e implementar uma união aduaneira como etapa pata a construção do mercado comum, que implique na presença das cinco liberdades básicas ${ }^{2}$, quais sejam, a livre circulação de bens, livre circulação de capitais, livre circulação de pessoas, de serviços, e a análise dessa ponência, a liberdade de concorrência ${ }^{3}$. Essas liberdades permitirão que exista uma integração plena entre as sociedades envolvidas. $\mathrm{Na}$ fase do mercado comum é que elas deverão estar confotmadas.

\footnotetext{
${ }^{2}$ Alguns autores ainda apresentam as liberdades como sendo apenas quatro, sem incluírem a livre concorrência, motivo pelo qual se suscitam ainda controvérsias doutrinárias. Dentre os que tratam como sendo apenas quatro ver LINÁN NOGUERAS, Diego J. El metcado interior: las cuatro libertades. In: RINOLDI LADMANN, Eve (coord.). Mercosur y Comunidad Europea, p. 89.93. Dentre os que tratam como sendo cinco ver PAZ, Vânia Beatriz Rey. Mercosul: a impossibilidade de harmonizar as legislações sindicais, p. 23 e 27, COST'A, Ligia Maura. A cooperação entre empresas no Mercosul. In: VeNTURA, Deisy de Freitas Lima (org.). O MERCOSUL em movimento, p. 22 e ainda ALMEIDA, Glizabeth Accioly Pinto de. Mercosul e União Européia: estrutura jurídico-institucional, p. 21 e 25. Ver tanbém sobre concorrência, espectalmente na União Européia, Op. cit., p. 25.29, e OLIVEIRA, Odete Maria de. União Européia: processo de integração e mutação, p. 251-265. Entretanto, DREYZIN DE KLOR trata a livre circulação de decisões como sendo a quinta liberdade fundamental do MERCOSUL. DREYZIN DE KLOR, Adriana. Hacia la quinta libertad fundanental del Mercosur. In: PIMENTEL, Luiz Otávio. (org.). MERCOSUL no Cenário Internacional: Direito e Sociedade, vol. 1, p. 17-29.

${ }^{3}$ Para SILVEIRA, inserida nos princípios gerais fundantes da ordem economica. SILVEXRA, Paulo Antônio Caliendo Velloso da. Defesa da concorrência no Mercosul: acordos entre empresas, abuso de posição dominante e concentrações, p. 43.
} 
Presentemente, no que concerne ao progressivo processo econômico de integração, o Mercosul palmilha numa região nebulosa: entre uma zona de live comércio no seu interior, ainda não totalmente implementada cos primeitos passos para o estabelecimento de uma união aduaneira frente a terceiros países.

Zona de livre comércio é a eliminação, através de um acordo, dos obstáculos tarifários e não-tarifários às exportações e importações comerciais dos produtos originários dos Estados-membros integrantes dessa livte zona. Estabelece-se uma liberdade, mantendo cada um dos Estados sua própria política tarifária com respeito aos terceiros Estados. Não envolve uma Tarifa Externa Comum (TEC). Porém, formulam-se as regras que definem a origem dos produtos comercializados.

A segunda fase da integração econômica é a contemplada por uma união aduaneira que implica, e esta é a sua principal característica diferenciadora, na definição de uma Tarifa Externa Comum (TEC). Ainda que imperfeita, essa fase foi iniciada no Mercosul, em $1^{\circ}$ de jancito de 1995.

$O$ fato de a rarifa externa ser única implica que certos aspectos da política comercial dos Estados-membros da União sejam coordenados, isto é, que haja uma maior coesão entre os parceiros.

Ademais dos estágios anteriores, o mercado comum requer a liberalização não apenas da circulação de bens, mas também de todos os demais fatores de produção, is to é, as pessoas, os serviços e os capitais, para os quais, a partir de então, não existam obstáculos para entrada e saída no interior de cada Estado-membro.

A passagem do período de transição de zona de livte comércio à união aduaneira, como etapas preliminares à última fase de mercado comum, apresenta-se como o momento mais apropriado para fomentar a questão das cinco liberdades.

Durante esse período de rransição, devem ser declinados os níveis em que essas liberdades serão realmente implementadas e as condições necessárias para viabilizá-las, além do incremento das políticas macroeconômicas. Nesse sentido, a observação do exemplo da Comunidade Européia, quanro às experiências positivas lá operadas, será pertinenre. Reconhece-se, por outro lado, que a liberdade de concorrência constiruirá, pela sua própria natureza e abrangência, um desafio permanente ao processo de inregração, dependendo, entre ourras variáveis, principalmente da vontade política das autoridades dos Estados-partes e dos seus nacionais à sua plena consolidação.

A construção de um espaço integrado de liberdades impõe-se a um mercado comum autêntico. Somente com a conformação da liberdade de concorrência, e das outras, será possível constituir o Mercosul em um verdadeiro mercado comum.

Neste sentido, a defesa do direito "que as empresas têm de, no âmbito de um bloco, serem submetidas às mesmas regras e exigências para que possam competir 
ern igual condição"s é um preceito fundamental pata a consagração da tetceira etapa da integração econômica.

\section{A União Européia e a liberdade de concorrência}

Diferentemente do que ocorre no âmbito do Mercosul, onde a matéria trata-se de direito in fleri, a hoje União Européia, desde há muito, tem regulada sua disciplina concorrencial. As regras comuns de concorrência, de fiscalidade e de aproximação das legislações compõem o Título $\mathrm{V}$ do Tratado de Roma de 25 de março de 1957, alterado pelo Tratado da União Européia (Tratado de Maastricht) de 07 de fevereiro de 1992 e por uma série de Regulamentos.

Segundo o ordenamento comunitário, são incompativeis com o mercado comum e proibidos todos os acordos entre empresas, todas as decisões de associações de empresas e todas as práticas concerradas que sejam suscetiveis de afetar o comércio entre os Estados-membros e que tenham por objetivo ou efeito impedir, restringir ou falsear a concorrência no mercado comum ${ }^{5}$.

Da mesma forma, é incompatível com o mercado comum e proibido, na medida em que tal seja suscetível de afetar o comércio nos Estados-membros, o fato de uma ou mais empresas explotarem de forma abusiva uma posição doninante no mercado comum ou numa parte substancial desse $e^{6}$.

No que se refere à interferência dos Estados nas regras de livre concorrência, o ordenamento comunitário notmatiza que são incompativeis com o mercado comum, na medida em que afetem as trocas comerciais entre os Estados-membros, os auxílios concedidos pelos Estados ou provenientes de recursos estatais, independentemente da forma que assumam, que falseiem ou ameacem falsear a concorrência, favorecendo certas empresas ou certas produções?.

Quanto à aproximação das legislações, o Conselho, deliberando por unanimidade, sob proposta da Comissão e após consulta do Parlamenro Europeu e do Comitê Econômico e Social, adota diretivas para a aproximação das disposições legislativas, regulamentares e administrativas dos Estados-membros que tenham incidência direta no estabelecimento ou no funcionamento do metcado comum ${ }^{8}$.

\footnotetext{
${ }^{4}$ SICVA NETO, Onlando Celso; MELO, Suzana Soares. Considenaçós sobre cooperação jurisdicional no âmbito do Mercosul. In: RODRIGUES, Horácio Wanderlei (org.). Solução de Controvérsias no MERCOSUL, p. 87.

5 Artigo 85 do Tratado de Roma.

${ }^{6}$ Artigo 86 do Tratado de Roma.

? Artigo 92 do Tratado de Roma.

* Artigo 100 do Tratado de Roma.
} 
Vê-se, com tais disposições, a preocupação do legislador comunitário no que diz respeito à possivel nefasta interferência dos Estados nas regras de concorrência e, principalmente, a intromissão de elementos meramente politicos nessas.

Ademais dessa ampla legislação, sua estrutura supranacional de decisóes dá a aplicação e interpretação necessárias para o cumprimento dos dispositivos comunitátios. A eficácia das decisões e a impottância do Tribunal de Justiça das Comunidades Européias para a afirmação da defesa da concorrência em nível comunitário impedem que empresas e governos adotem comportamentos políticos ou econômicos lesivos à concortência. O Direito Comunitário da livre concorrência é um direito diretamente aplicável a todos os Estados-membros (supranacionalidade), tendo como destinatários diretos e finais, no caso, as empresas.

Ante o exposto, é cabível afirmat que sem a tomada dessas precauções, especialmente o controle sobre os Estados, a consolidação do mercado comum europeu não teria sido possível.

\section{O Mercosul e a liberdade de concorrência}

O Tratado de Assunção silenciou sobre o regramento da liberdade de concorrência, como um todo, e também quanto às práticas desleais dessa. Tal fato motivou a formulação do Protocolo de Defesa da Concorrência. A Decisão do Conselho Mercado Comum númeto 18/96, de 17 de dezembro de 1996, não incluiu a cláusula de proibição às ajudas dos Estados, que era a proposta da Argentina. Tal Protocolo, contudo, se encontra em fase de ratificação pelos países, sem qualquer previsão para entrada em vigor. Nem mesmo os países do Mercosul que não têm ordenamentos internos sobre a liberdade de concorrência, o ratificaram, ato que poderia suptir a lacuna do Paraguai e Uruguai.

Tampouco a Comissão Mista de Comércio, órgão intergovernamental com capacidade decisória, criado pelo Protocolo de Ouro Preto, tem, reconhecidamente, aplicado instrumentos de política comercial.

$O$ fato desses países não disporem de legislação específica pode ser observado com bons olhos, pois permititia uma mais fácil harmonização das legislações de concorrência por, em verdade, não existirem. É pertinente lembrar que os países do Mercosul são, também, membros do Acordo Geral de Tarifas e Comércio (GAT'T). Esse Acordo, atualmente em sede de Organização Mundial do Comércio, possui segras concernente à liberdade de concorrência e políticas de subsídios, às quais poderiam ser harmonizadas, coordenadas ou até mesmo coexistir.

O Brasil tem sua disposição concortencial na Lei $n^{\circ} 8.137 / 90$, que apresenta os atos contrários à orden econômica como comuns, na Lei $n^{\circ} 8.158 / 91$, que tem por fundamento as normas de defesa da concorrência, e, especialmente, na Lei $\mathrm{n}^{\circ} 8.884$, 
de 11 de junho de 1994, que transformou o Conselho Administrativo de Defesa Econômica (CADE) em autarquia e dispôs sobre a prevenção e a repressão às infraçōes contra a ordem econômica. Essa Lei é aplicável às pessoas físicas ou jurídicas de direito público ou privado.

A Argentina dispõe de recente legislação infra-constitucional sobre a matéria, qual seja a Lei de Defesa de Concorrência de 26 de agosto de 1999, que modificou a anterior de número 22.262/80. Instituiu una Tribunal Nacional de Defesa da Concorrência, uma espécie de Conselho Administrativo de Defesa Econômica deles, para aplicá-la e controlar seu cumprimento. Como deve ser, proíbe o abuso de posição dominante e impede acordos entre firmas que restrinjam, limirem, falseiem ou distorçam a concorrência ou o acesso ao mercado. Estabelece, ainda, quais condutas ou acordos serão proibidos. Define, em seu contexto, o que é posição dominante e concentração econômica.

Mesmo na hipótese de ratificação pelos quatro países do Protocolo, ainda vale lembrar que, diferenremente da União Européia, a estrutura intergovernamental do Mercosul não produz manifestação quanto às gatantias de seu cumprimento e tampouco prevalece o princípio da primazia do Dircito de Integração. Por tal e outros motivos é que a cada dia se avolumam os doutrinadores internacionalistas regionais simpáticos à criação de um tribunal supranacional para dirimir conflitos no âmbito do Mercosul, assegurando interpretação e aplicação dos dispositivos emitidos pelo bloco, a exemplo da União Européia. Eventuais problemas de descumprimento das regras de concorrência, atualmente são regidos por organismos intergovernamentais, em especial os instituídos pelo Protocolo de Brasília.

Assim, para o atingimento da etapa de mercado comum, imprescindível se faz a presença das cinco liberdades econômicas fundamentais, entre elas a de concorrência. Um sistema de livre concorrência requer que os Estados-partes se abstenham de conceder às empresas subsídios que falseiem, ou ameacem falsear essa liberdade, a produção ou o comércio entre eles.

Nota-se, atualmente, no Brasil, uma preocupação com o assunto da liberdade de concor rência. Veja-se a grande repercussão dos trabalhos do Conselho Administrativo de Defesa Econômica, recentemente observado pela sua atuação na questão da fusão de cervejarias nacionais, e, anteriormente, nas questões que envolveram a marca de produtos de higiene Kolynos, a Cervejaria Miller ${ }^{10}$ e a questão Gerdau-Pains, entre outras. Ou ainda, no plano internacional, a mídia dada ao caso Microsofr, em seu julgamento, nos Estados Unidos da América, por sua política conjugada de vendas e abuso de posição dominante.

Noutra questão também já surgem discussões. A chegada de provedores de acesso grátis à internet, segundo os proprietários dos provedores onerosos, é flagrante quebra das regras de livre concorrência. Ao contrário, para os primeiros, isto que é, sim, exercício de livre concorrência.

\footnotetext{
2 Ato de Concentração número 27/95, de 18 de setembro de 1996.

${ }^{10}$ A to de Concentração número $58 / 95$, de 11 de junho de 1997.
} 
Antes, a retirada do monopólio estatal da exploração do petróleo da empresa Petrobrás pôde ser entendida como uma política governamental de garantias de livre concorrência. Assim agindo, o Brasil abriu este ramo de negócios a outras empresas, antecipando-se à disputa de agentes econômicos para a satisfação da escolha de um cliente ou adquirente de produtos.

\section{Políticas públicas e a liberdade de concorrência}

Outras políticas eminentemente estatais são nefastas. A título de exemplo, poder-se-ía indicar a guerra fiscal em curso no Brasil, entre as unidades da Federação. Algumas, politicamente mais forres, mesmo comprometendo suas economias, alcançam a algumas empresas vantagens que as colocam à frente das demais do mesmo ramo e capacidade. Neste sentido, é desmedida a disputa entre empresas umas, e outras que têm como sustentáculo dos seus programas e ações a tutela e o amparo político e econômico de uma entidade pública. $A$ decisão política de um Estado de estender subsídios econômicos que ameacem falsear ou falseiem a concorrência se constitui num grave desvirtuamento das regras dessa liberdade.

A guerra fiscal prejudica o desenvolvimento e desestimula investimentos nacionais e estrangeiros ao criat uma concorrência perversa entre empresas e introduzir elementos políticos nas regras econômicas.

Contra devetia insurgit-se o Estado. Isto é, deveria aplicar o conjunto das regras que têm por objeto sua intervenção na vida econômica para garantir o estabelecimento de empresas, a competição delas no metcado, que esta não seja falseada por meio de práticas nocivas à concorrência, e o correto direcionamento das verbas públicas, o que se entende por promoção da justiça econômica. Mas não o faz. Ocorre que a outros objetos têm servido a tutela estatal. A outorga de subsídios a certas empresas, propiciandolhes uma injusta vantagem concorrencial sobre as empresas que não se valem dc benefícios governamenrais, deixa em aberto a pergunta de se tal ingerência é necessária ou nefasta ao direito de concorrência, que precisa ser livre para o atingimento da fase de mercado comum. Veja-se, ainda, o progtama de ajuda aos bancos em dificuldades ou outro programa de salvação de empresas quaisquer.

Esse tratamento deixa margem para a proteção estatal ao livre metcado e à observância das regras de concorrência, da forma que se opera, colisionat com a necessátia abertura em um processo de integração. Até porque a tutela poderá ferir regras do Direito de Integração.

Todas essas argumentações são feitas fechando os olhos para as situações em que as próprias empresas públicas inibem a concortência. Em que pese ter havido, nos últimos tempos, um grande número de processos de privatização, durante longa data as empresas estatais se valeram de tratamento diferenciado, concessão de subsídios e outras políticas. 
Como se observa, o risco da quebra da liberdade de concorrência é muito maior quando é partícipe o próprio Estado, no momento em que implementa políticas não compativeis com aquelas.

Da mesma forma, transcendendo essa análise interna, quando um país toma a decisão política de relativizar sua legislação e garantia trabalhista, está dando margem ao estabelecimento, nele, de empresas internacionais em busca de melhores condições econômicas e menores custos. De forma direta, em prejuízo ao trabalhador, este país estará favorecendo a prática de dumping social. A vantagem da desregulamentação trabalhista estatá induzindo, em flagrante quebra das regras de concorrência, que deveriam ser baseadas na competitividade ou posição geográfica, por exemplo, empresas a nele se estabelecerem.

No plano das negociações do Mercosul, a dererminação de quotas de importação e exportação de determinados produtos fere o princípio da livre concorrência. As quotas são determinações governamentais praricadas durante certo lapso no qual somente um valor ou uma quantidade determinada de um produto poderá ou deverá ser comercializada. Representam, por óbvio, um obstáculo à liberdade de concorrência.

No mínimo o produtor nacional vê seu produto pteterido, tendo por base um acordo, na maioria das vezes político, no qual sequer fez parte, tampouco foi representado. No outro pólo, um consumidor que deseje determinado produto que teve sua quota esgotada, não poderá fazer uso de seu direito de escolha.

No ano passado, a Argentina demonstrou não ter se adequado, no prazo previsto, às metas instituídas pelo bloco. Tal inadequação, e a desvalorização do Real frente ao Dólar, decisão política e econômica, fez com que ela se visse obrigada a instituir cláusulas de salvaguarda frente ao Brasil, especialmente para os setores de calçados, frangos, têxteis e regime automotivo. Tal medida quase desencadeou o rompimento do Acordo Mercosul.

A desvalorização do Real provocou desmedida concorrência entre empresas brasileiras e argentinas, essencialmente em dois aspectos: o volume de exportações de produtos brasileiros para o referido país e a importação de empresas inteiras em curso entre Argentina e Brasil, ambos em favor desse último. Acontecimento como esse é bom pata o Brasil, em análise isolada e não exaustiva. Mas, sistematicamente, devido ao descompasso provocado no crescimento econômico, ruim para o processo de integração.

Quanto à imposição de clálusulas, no Brasil, assim também procedeu o Estado de São Paulo. Em referido momento o atual governador criou salvaguardas para proteger seu Estado contra a guerra fiscal. 


\section{Considerações Finais}

Haja visto o exposto, pretendeu-se evidenciar aspectos da influência das decisões políticas e das vantagens econômicas públicas oferecidas a determinados entes empresariais, públicos ou privados, nacionais ou internacionais, por entidades públicas dos ou pelos próprios Estados-partes do Mercosul, nas regras da liberdade de concorrência.

Como por exemplo a citada desregulamentação das regras trabalhistas, a concessão de subsídios que falseiem, ou ameacem falsear a concorrência e o comércio, e a iminente possibilidade da prática de dumping social pelos países do bloco Mercosul. Ou também por decisões políticas e auxilios financeiros, fiscais e orçamentários, prejudiciais à livre concorrência e causadores de impedimentos ao atingimento da fase de mercado comum. E, conseqüentemente, ao avanço do principal bloco econômico que fazemos parte a essa etapa posterior.

\section{Então, conclui-se dizendo que:}

1. Os Estados têm, como uma de suas funções, o dever de garantir a liberdade de concorrência comercial. Para tal, valeñ-se dos mecanismos que estão à disposição deles. Ocorre que essa função dos Estados tem sido utilizada com outras finalidades;

2. Tais práticas, da forma que são manifestadas, desvirtuadas de seus objetivos, muitas vezes fundadas em decisões meramente políticas, não cumprem os objetivos de disciplinar a concorrência;

3. Ante a isso, não se conforma a necessária liberdade de concorrência, imprescindivel de assim estar para o atingimento da terceira e última fase do processo de integração do Mercosul;

4. Faz-se necessário, no território compreendido pelo Mercosul, a ratificação da Decisão/CMC n ${ }^{\circ}$ 18/96, conhecida como Protocolo de Defesa da Concorrência no Mercosul, da Decisão/CMC n ${ }^{\circ} 20 / 94$, sobre politicas públicas que distorcem a competitividade, e da Decisão/CMC n²1/94, também sobre defesa da concorrência, uma vez que o assunto não foi considerado no Tratado de Assunção, e o surgimento de ordenamentos internos que redirecionem a atuação dos Estados no cumprimento de seus deveres de regular e garantit a liberdade de concorrência, entendendo ser esta um dos pilares fundamentais à conctetização do Mercosul, quando do atingimento da fase de mercado comum;

5. Outrossim, entende-se necessário adequar ao conhecimento a ser buscado a experiência da integração da União Européia, porque similar, porém, em dimensão teconhecidamente menor, mas pertinente ao ptocesso de integração do Mercosul. 


\section{BIBLIOGRAFIA}

ALMEIDA, Elizabeth Accioly Pinto de. Mercosul e União Européia: estrutura jurídico-institucional. Curitiba: Juruá, $1996.159 \mathrm{p}$.

CELLI JUNIOR, Umberto. Regras de concorrência no Direito Internacional moderno. Porto Alegre: Livraria do Advogado, 1999. 252 p.

COSTA, Ligia Maura. A cooperação entre empresas no Metcosul. In: VENTURA, Deisy de Freitas Lima (org.). O MERCOSUL em movimento. Porto Alegre: Livraria do Advogado, 1995. p. 21-38.

DECISÃO do Conselho Mercado Comum n. 20/94.

DECISÃO do Conselho Metcado Comum n. 21/94.

DEL'OLMO, Florisbal de Souza. Direito Intemacional Privado: abordagens fundamentais, legislação, jurisprudências. Rio de Janeiro: Forense, 1999. 247 P.

DREYZIN DE KLOR, Adriana. Hacia la quinta libertad fundamental del Mercosur. In: PIMENTEL, Luiz Otávio (org.). MERCOSUL no cenário Intemacional: Direito e Sociedade. v. 1. Curitiba: Juruá, 1998. p. 17-29.

FARIA, Werter R. Direito da Concorrência e Contrato de Distribuição. Porto Alegre: Sergio Antonio Fabris Ediror, 1992. 144 p.

JAEGER JUNIOR, Augusto. Mercosul: a exclusão do cidadão nos processos de constituição e integração. In: PIMENTEL, Luiz Otávio (org.). MERCOSUL no cenário internacional: Direito e Sociedade, v. 2, p. 9-17. . Mercosule a livre circulação de pessoas. São Paulo: LTr, 2000.190 p.

LIÑÁN NOGUERAS, Diego J. El mercado interior: las cuatro libertades. In: RINOLDI LADMANN, Eve (coord.). Mercosur y Comunidad Europea. Buenos Aires: Ciudad Argentina, 1995. p. 89-93.

MARTINS, Eliane Maria Octaviano. Defesa da concorrência e supranacionalidade. In: Revista Jurídica Consulex. Brasilia: Consulex, a. 3. v. 1. n. 31, 1999. p. $48-49$.

OLIVEIRA, Odete Maria de. União Européia: processos de integração e mutações. Curitiba: Juruá, 1999. 486 p.

PAZ, Vânia Beatriz Rey Mercosul: a impossibilidade de harmonizar as legislações sindicais. Curitiba: Juruá, 1999. 152 p.

PIMENTEL, Luiz Otávio (org.). MERCOSUL no Cenário Internacional: Direito e Sociedade. Curitiba: Juruá, 1998. 2 v. 
PROTOCOLO de Brasília, de 17 de dezembro de 1991.

PROTOCOLO de Defesa da Concorrência no Mercosul, Decisão/CMC n. 18/96, de 17 de dezembro de 1996.

PROTOCOLO de Ouro Preto, de 17 de dezembro de 1994.

RINOLDI LADMANN, Eve (coord.). Mercosur y Comunidad Europea. Buenos Aires: Ciudad Argentina, 1995. 235 p.

RODRIGUES, Horácio Wanderiei (otg.). Solụ̧a de Controvérsias no MERCOSUL. Porto Alegre: Livraria do Advogado, 1997. 164 p.

RUIZ DÍAZ LABRANO, Roberto. El Mercosur, marco juridico institucional, analisis $y$ perspectivas de sus normas derivadas. Asunción: Intercontinental, 1993.198 p.

$1998.733 \mathrm{p}$. Mercosur: Integración y Derecho. Buenos Aires: Ciudad Argentina,

SILVA NETO, Orlando Celso; MELO, Suzana Soares. Considerações sobre cooperação jurisdicional no âmbito do Mercosul. In: RODRIGUES, Horácio Wanderlei (org.). Solução de Controvérsias no MERCOSUL. Porto Alegre: Livraria do Advogado, 1997. p. 81-111.

SILVEIRA, Paulo Antônio Caliendo Velloso da. Defesa da concorrência no Mercosul: acordos entre empresas, abuso de posição dominante e concentrações. São Paulo: $L \mathrm{Tr}, 1998.317 \mathrm{p}$.

STRENGER, Irineu. Direito do comércio internacionale Lex Mercatoria. São Paulo: LTR, 1996. 222 P.

VENTURA, Deisy de Freitas Lima. OMERCOSUL em Movimento. Porto Alegre: Livraria do Advogado, 1995. $172 \mathrm{p}$. 